\title{
Ubiquitin-like with PHD and ring finger domains 2 is a predictor of survival and a potential therapeutic target in colon cancer
}

\author{
SU LU ${ }^{1}$, DONGWANG YAN ${ }^{2}$, ZEHUA WU ${ }^{2}$, TAO JIANG ${ }^{2}$, JIAN CHEN $^{2}$, \\ LIN YUAN ${ }^{1}$, JUN LIN ${ }^{1}$, ZHIHAI PENG ${ }^{2}$ and HUAMEI TANG ${ }^{1}$ \\ Departments of ${ }^{1}$ Pathology and ${ }^{2}$ General Surgery, Shanghai Jiaotong University \\ Affiliated First People's Hospital, Shanghai 200080, P.R. China
}

Received November 28, 2013; Accepted January 29, 2014

DOI: $10.3892 /$ or.2014.3035

\begin{abstract}
In the present study, we investigated the expression of ubiquitin-like with PHD and ring finger domains 2 (UHRF2) in colon cancer and adjacent normal tissues and estimated the clinicopathological significance and predictive value of UHRF2 expression in colon cancer. Using quantitative real-time PCR, tissue microarray (TMA), western blot analysis and immunohistochemical staining, we evaluated UHRF2 mRNA and protein levels in tumor tissues and paired adjacent normal epithelium. We found that UHRF2 was upregulated at both the transcriptional and translational levels in tumor tissues. Immunohistochemical detection of UHRF2 on a TMA containing 203 paired specimens showed that increased cytoplasmic UHRF2 was significantly associated with clinical stage, depth of invasion, nodal involvement, tumor histologic grade and the presence of metastasis. Patients with UHRF2-positive tumors had a much lower diseasefree survival [hazard ratio (HR) 9.511, $\mathrm{P}<0.001$ ] and overall survival (HR 9.820, $\mathrm{P}<0.001)$. Univariate and multivariate analyses were performed to determine the correlation between these parameters and the clinical and pathological variables of the study population verifying that UHRF2 immunoreactivity emerged as an independent prognostic factor in the multivariate analysis. UHRF2 may contribute to the progression of colon carcinogenesis and function as a novel prognostic indicator after curative operation.
\end{abstract}

\section{Introduction}

Colon cancer is one of the most common malignancies in the world and results from an accumulation of genetic and

Correspondence to: Dr Huamei Tang, Department of Pathology, Shanghai Jiaotong University Affiliated First People's Hospital, 85 Wujin Road, Shanghai 200080, P.R. China

E-mail: huamei-tang@hotmail.com

Dr Zhihai Peng, Department of General Surgery, Shanghai Jiaotong University Affiliated First People's Hospital, 85 Wujin Road, Shanghai 200080, P.R. China

E-mail: pengpzh@hotmail.com

Key words: ubiquitin-like with PHD and ring finger domains 2, colon cancer, progression, prognosis, tissue microarray epigenetic aberrations (1). It is the second leading cause of cancer mortality in the United States with $\sim 52,000$ deaths and 143,000 cases expected in 2012 (2) and ranks the third leading cause of cancer mortality worldwide (3). In addition, changes in lifestyle and nutrition have led to the rise in colon cancer incidence in China and other economically transitioning countries over the past few decades (4). In spite of advances in screening and prevention, early detection, adjuvant therapy and treatment of metastatic disease, colon cancer remains the major cause of cancer morbidity and mortality. Evidence has been provided by molecular investigations that multiple alterations in genes of the striking signaling pathway, including adenomatous polyposis coli protein (APC), $\beta$-catenin and c-myc, are involved in colonic carcinogenesis $(5,6)$. Despite existing intensive study, the molecular mechanisms underlying the development and progression of colon cancer remain poorly understood. It is of great clinical importance to further investigate the molecular mechanisms of this cancer and to find valuable early diagnostic markers with high specificity and sensitivity as well as novel therapeutic targets.

The ubiquitin proteasome system (UPS) regulates the ubiquitination, and thus the degradation and turnover, of many proteins crucial to cellular regulation and function (7). Aberrancies within the UPS pathway can result in a malignant cellular phenotype which can lead to several types of human malignant cancer $(8,9)$. Fundamental to the specificity of this system are ubiquitin-protein ligases (E3s) (10). Ubiquitin-like with PHD and ring finger domains 2 (UHRF2), a member of the UHRF [ubiquitin PHD really interesting new gene (RING) finger] family, is a nuclear E3 ubiquitin ligase mapped to 9p23$24.1(11,12)$.

UHRF2 comprises diverse domains including the ubiquitin-like (UBL) domain, tandem Tudor domain (TTD), plant homeo domain (PHD) finger domain, SET and RING associated (SRA) domain and RING finger domain (11-13). Due to its multiple domains, UHRF2 has such a complex function that it is involved in cell cycle network, the epigenetic system and the UPS. On account of its three different network modules, UHRF2 plays a contradictory role in tumorigenesis. Using a cancer outlier profile analysis identified that DNA copy number loss of the UHRF2 gene in a variety of malignancies related to the brain (14). On the contrary, UHRF2 has been proven to play a role as an oncogene in breast cancer cells (15). 
However, the clinicopathological significance and mechanism of UHRF2 involvement in the aggression of colon cancer is not completely understood.

The present study sought to assess the hypothesis that UHRF2 expression is dysregulated in colon cancer at both the mRNA and protein levels and its predictive value in colon cancer. Immunohistochemistry was used to explore the expression of UHRF2 both in primary colon cancer specimens and paired adjacent normal mucosa tissue and investigated whether UHRF2 may be used as an independent biomarker to predict metastasis and prognosis in patients with colon cancer.

\section{Materials and methods}

Patients and specimens. The Ethics Committee of Shanghai Jiaotong University Affiliated First People's Hospital approved this study. A total of 203 colon cancer patients were enrolled; all provided informed consent according to a protocol approved by the Institutional Review Board of the Shanghai First People's Hospital. The patients permitted surgical resection of tumors by the same surgical team at the Shanghai Jiaotong University affiliated Shanghai First People's Hospital Gastrointestinal Cancer Center between January 2001 and December 2003. No patients had received therapy prior to surgery. There were 86 men and 117 women with a mean age of $65 \pm 15$ years (range, 22-95 years). Formalin-fixed, paraffin-embedded samples for immunohistochemistry were obtained from the 203 colon carcinoma tissues and paired normal mucosal tissue taken from a segment of the resected specimens that was the farthest from the tumor $(>10 \mathrm{~cm})$. All tissues were histologically confirmed to be adenocarcinoma of the colon. Patient follow-up was carried out according to the National Comprehensive Cancer Network Practice Guidelines in colon cancer (Engstrom PF.2005; 3:468-91). Disease-free survival (DFS) and overall survival (OS) rates were defined as the interval from the initial surgery to clinically or radiologically proven recurrence/metastasis and death, respectively. The final follow-up was on June 29, 2008 with a median patient follow-up time for survivors of 61 months (range, 9-89 months). Detailed patient demographic information is shown in Table I. Vascular invasion was defined as vessel wall occlusion or destruction, accompanied by a surrounding fibroinflammatory reaction (16).

RNA extraction, reverse transcription $P C R$ and quantitative real-time PCR. Total RNA in 40 paired, frozen primary colon cancer tissues, and adjacent normal mucosa were extracted according to the manufacturer's instructions (Qiagen, Hilden, Germany). One microgram of total RNA from each sample was subjected to first-strand complementary DNA synthesis using an A3500 RT-PCR System ${ }^{\circledR}$ according to the recommendations of the manufacturer (Promega Corporation, Madison, WI, USA). To confirm UHRF2 gene expression in colon tumors, relative UHRF2 mRNA levels were assessed by quantitative real-time PCR (qPCR) using Mastercycler ep realplex $^{\circledR}$ (Eppendorf, Hamburg, Germany) with an IQTM SYBR-Green Supermix kit (Bio-Rad, Berkeley, CA, USA) according to the manufacturer's instructions and using the following thermal cycling conditions: initial denaturation $\left(10 \mathrm{~min}\right.$ at $\left.95^{\circ} \mathrm{C}\right)$ followed by 40 cycles of denaturation $(10 \mathrm{sec}$ at $\left.95^{\circ} \mathrm{C}\right)$, annealing $\left(15 \mathrm{sec}\right.$ at $\left.58^{\circ} \mathrm{C}\right)$ and elongation $(1 \mathrm{~min}$ at
Table I. Expression of UHRF2 in normal and colon cancer tissues.

\begin{tabular}{lccc}
\hline $\begin{array}{l}\text { Expression of } \\
\text { UHRF2 }\end{array}$ & $\begin{array}{c}\text { Normal tissue } \\
(\%)\end{array}$ & $\begin{array}{c}\text { Tumor tissue } \\
(\%)\end{array}$ & P-value \\
\hline All subjects & & & \\
No. of subjects & 203 & 203 & $<0.001^{\mathrm{a}}$ \\
Negative & $132(65.0)$ & $70(34.5)$ & \\
Weak & $38(18.7)$ & $57(28.1)$ & \\
Positive & $33(16.3)$ & $76(37.4)$ & \\
Subjects without LNM & & & \\
No. of subjects & 108 & 108 & $0.003^{\mathrm{a}}$ \\
Negative & $77(71.3)$ & $53(49.1)$ & \\
Weak & $16(14.8)$ & $32(29.6)$ & \\
Positive & $15(13.9)$ & $23(21.3)$ & \\
Subjects with LNM & & & \\
No. of subjects & 95 & 95 & $<0.001^{\mathrm{a}}$ \\
Negative & $55(57.9)$ & $18(18.9)$ & \\
Weak & $18(23.2)$ & $25(26.3)$ & \\
Positive & $22(18.9)$ & $52(54.7)$ & \\
P-value & 0.131 & $<0.001^{\mathrm{a}}$ & \\
& & &
\end{tabular}

aP-value derived from $\chi^{2}$ test. LNM, lymph node metastasis; UHRF2, ubiquitin-like with PHD and ring finger domains 2 .

$72^{\circ} \mathrm{C}$ ). Glyceraldehyde-3-phosphate dehydrogenase (GAPDH) was used as an internal control. The primers for qPCR were: UHRF2 sense, 5'-TTCTTGCTCCTGTCGTGTATGT-3' and antisense, 5'-CTTGAGTCTTTCACCAGCCTTT-3'; GAPDH sense, 5'-GTCCACCACCCTGTTGCTGTA-3' and antisense, 5'-CTTCAACAGCGACACCCACTC-3'. Each reaction was repeated at least three times, and then the mean UHRF 2 mRNA level for each tumor was compared with the level of its matched non-tumorous tissue. The fold-change $\left(2^{-\Delta \Delta C t}\right)(17)$ in UHRF2 expression in each paired sample was calculated using the formulas: UHRF2 $\Delta \mathrm{Ct}=($ Avg.UHRF2_Ct - Avg.GAPDH_Ct $)$, $\mathrm{UHRF} 2 \Delta \Delta \mathrm{Ct}=\left(\mathrm{UHRF} 2 \Delta \mathrm{Ct} \_\right.$tumor-UHRF2 $\Delta \mathrm{Ct}$ _non-tumor $)$.

Western blot analysis. Total proteins were extracted from 8 paired frozen colon tumor and adjacent normal tissues using radioimmunoprecipitation assay (RIPA) lysis buffer (50 mM Tris $\mathrm{pH} 7.4,150 \mathrm{mM} \mathrm{NaCl}, 1 \% \mathrm{NP}-40,0.5 \%$ sodium deoxycholate and $0.1 \%$ SDS) with a protease inhibitor cocktail $(0.89 \mu \mathrm{g} / \mu \mathrm{l}$; Sigma-Aldrich) and phenylmethanesulfonyl fluoride $(17.4 \mu \mathrm{g} / \mu \mathrm{l})$ and quantified using a BCA protein assay kit according to the manufacturer's instructions (Beyotime Biotechnology Co., Jiangsu, China). Equivalent amounts of protein were separated by electrophoresis on a $9.0 \%$ sodium dodecyl sulphatepolyacrylamide gels and transferred onto polyvinylidene difluoride (PVDF) membranes, which were blocked with $5 \%$ non-fat dry milk in $0.05 \%$ PBS-T for $1 \mathrm{~h}$ at room temperature, followed by incubation with the rabbit anti-UHRF2 polyclonal antibody (1:500) or anti- $\beta$-actin monoclonal antibody $(1: 2,000)$ (both from Abcam, Cambridge, UK) overnight at $4^{\circ} \mathrm{C}$. After washing with TBST buffer, the membranes were incubated with a goat-anti-rabbit $\mathrm{IgG}$ HRP-conjugated secondary antibody (1:5,000; Santa Cruz 
Biotechnology, Inc., Santa Cruz, CA, USA) for $2 \mathrm{~h}$. The membranes were washed, and bound antibodies were detected by enhanced chemiluminescence (Millipore) according to the manufacturer's instructions and were exposed to X-ray film. The abundance of each protein was determined and normalized against $\beta$-actin expression.

Tissue microarray (TMA) construction and immunohistochemistry. TMA construction was undertaken as previously reported (18). Briefly, paraffin-embedded TMA sections were dewaxed and rehydrated before antigen retrieval was carried out. Immunohistochemistry was performed to further evaluate the histological expression of UHRF2. UHRF2 and Ki-67 expression were detected on the TMAs following preheated $\left(95-98^{\circ} \mathrm{C}\right)$ citrate buffer $(\mathrm{pH} 6.0)$ for $10 \mathrm{~min}$ aimed at antigen retrieval. Immunolabeling was carried out using a primary antibody against UHRF2 (1:50; Abcam) and the proliferation index Ki-67 (1:50; Dako Cytomation, Copenhagen, Denmark). Sections were incubated overnight at $4^{\circ} \mathrm{C}$ and then incubated with the secondary antibody (EnVision System, Dako) for $1 \mathrm{~h}$ at room temperature. After rinsing three times in PBS for $10 \mathrm{~min}$ each, the sections were incubated with 3,3-diaminobenzidine tetrahydrochloride (DAB) liquid for $1 \mathrm{~min}$, counterstained with Mayer hematoxylin, dehydrated and then mounted. The negative control was prepared with normal tissue and without anti-UHRF2 antibody incubation.

Evaluation of immunohistochemical staining. Immunoreactivity was evaluated independently by three researchers who were blinded to patient outcomes (double-blinded) on the basis of the intensity and extent of staining (19). The staining intensity for UHRF2 was graded as 0 (no staining), 1 (mild staining), 2 (moderate staining) and 3 (intense staining). The staining extent was scored using the scale as follows: 0 (no staining of cells), 1 (<10\% of tissue stained positive), 2 (10-50\% stained positive), 3 ( $>50 \%$ stained positive). The final staining score was defined as the sum of the intensity and extent scores. The specimens were divided into three groups according to their overall scores as follows: 0-2, expression; 3-4, weak expression; 5-6, strong expression. The Ki-67 proliferation index was on the basis of the percentage of cells with positive nuclear staining and was divided into two groups selecting $10 \%$ positively staining nuclei as the cutoff point: negative $(\leq 10 \%$ of cells with positive nuclei) and positive ( $>10 \%$ of cells with positive nuclei) (20). In cases of discrepant assessments, the sections were re-investigated by both pathologists under a multi-head microscope until consensus was achieved.

Statistical analyses. All statistical analyses were performed using the SPSS 16.0 statistics software package (SPSS Inc., Chicago, IL, USA). Paired t-tests were carried out to indicate the expression $(\triangle \mathrm{CT})$ of UHRF2 in normal and adjacent cancer tissues. The $\chi^{2}$ test or Fisher's exact test, where appropriate, for proportionality was used to analyze the relationship between the expression of UHRF2, the Ki-67 proliferation index and the clinicopathological variables. The Kaplan-Meier method was applied to calculate the survival rates and the differences between the survival curves were examined by the log-rank test. Univariate Cox proportional hazards regressions were used to estimate the individual hazard ratio (HR) for the DFS and OS.

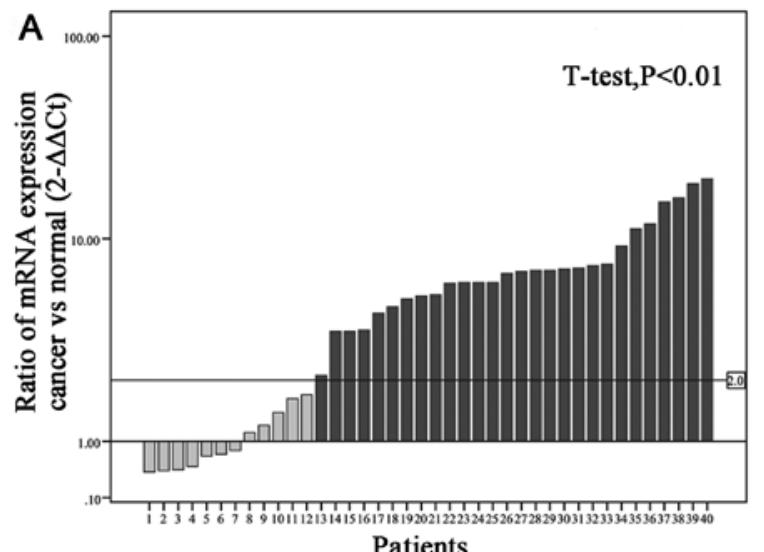

Patients

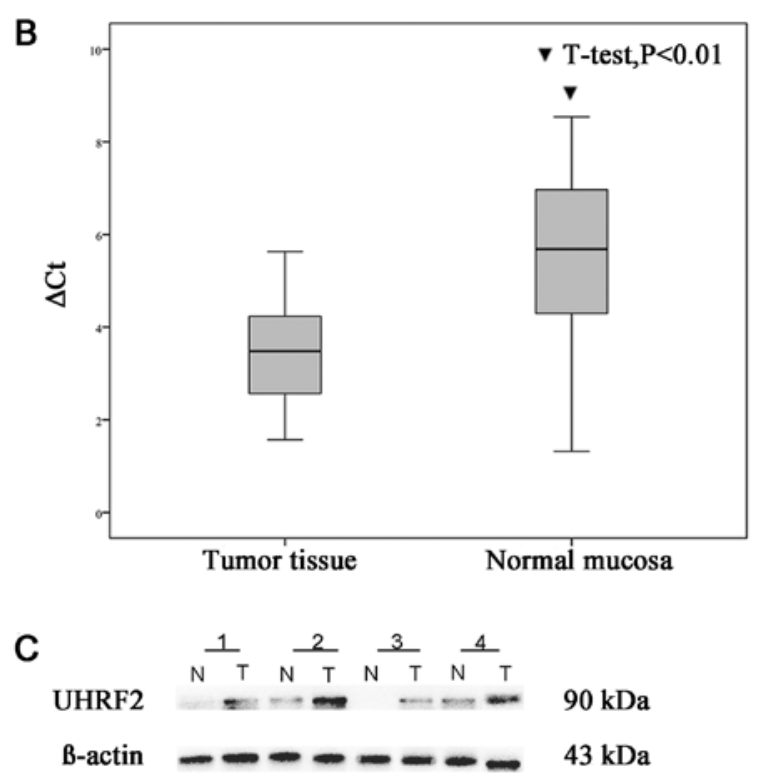

Figure 1. Expression of UHRF2 in colon tumorous tissues and adjacent normal mucosa. Real-time PCR analysis of UHRF2 mRNA expression in 40 paired colon tumor samples and adjacent normal mucosa. For each sample, the relative UHRF2 mRNA level was normalized using GAPDH expression. (A) A logarithmic scale of $2^{-\Delta \Delta C T}$ was used to represent the fold-change. (B) Data are presented as the median (line) $\Delta \mathrm{Ct}$ value with boxed 25 th and 75 th percentiles. The data range is represented by the upper and lower bars. (C) Western blot analysis of UHRF2 protein expression in 4 representative paired colon tumor tissues, $\beta$-actin is the loading control. $\mathrm{P}<0.001$. UHRF2, ubiquitin-like with PHD and ring finger domains 2 .

The significant variables in the univariate analyses $(\mathrm{P}<0.05)$ were then put into the multivariate analysis. A P-value of $<0.05$ was considered to indicate a statistically significant difference.

\section{Results}

Upregulation of UHRF2 expression in primary colon cancer as compared with adjacent normal mucosa. UHRF2 gene expression was confirmed by real-time PCR analysis of primary colon cancer and adjacent normal mucosa from 40 patients with colon cancer with GAPDH as the internal reference. Of the 40 paired cases, 28 (68\%) colon cancer tissues showed at least a two-fold increase in UHRF2 mRNA level compared with that of the adjacent non-cancerous mucosa (Fig. 1A). In patients with colon cancer, the expression $(\Delta \mathrm{Ct})$ of UHRF2 was $3.51 \pm 1.072$ in tumor tissue and 

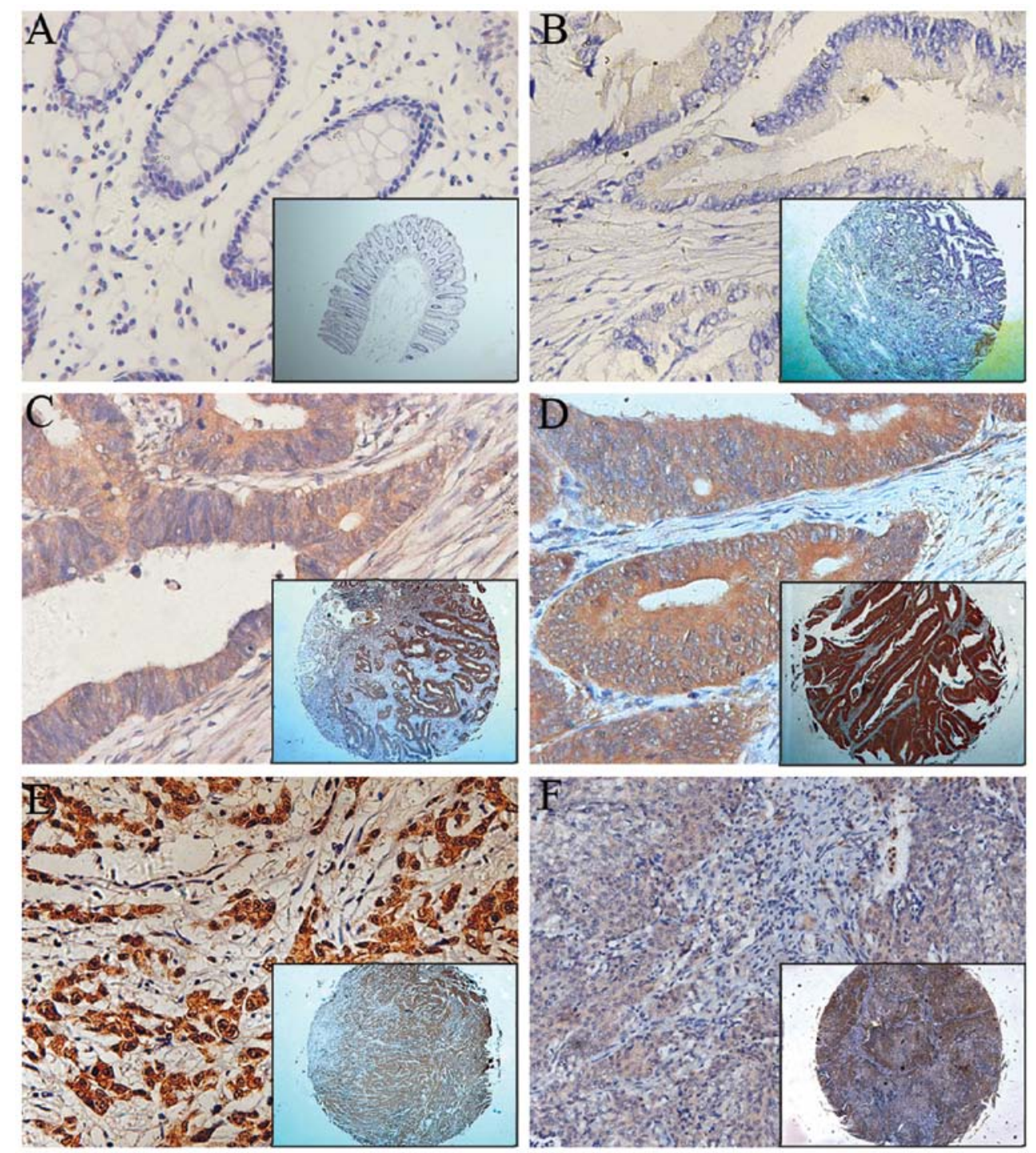

Figure 2. Immunohistochemical staining of UHRF2 expression in normal tissue and colon cancer. (A) Negative-UHRF2 expression in normal colonic epithelium and (B) well-differentiated tumor. (C) Weak UHRF2 staining in a well and (D) moderately-differentiated colon tumor. (E) Diffuse, intense UHRF2 staining in moderately and (F) poorly-differentiated colon tumors. Strong RBBP6 staining in a colon cancer lymph node metastasis. Original magnification x400 (x50 for insets). UHRF2, ubiquitin-like with PHD and ring finger domains 2.

$5.4530 \pm 1.772$ in normal tissue $(\mathrm{P}<0.001$; Fig. $1 \mathrm{~B})$. The $2^{-\Delta \Delta \mathrm{Ct}}$ was $5.78 \pm 4.93$ (range $0.58-19.70$ ). This difference in UHRF2 mRNA expression was significant ( $\mathrm{P}<0.001$; Fig. 1). This suggests that UHRF2 mRNA level was upregulated in cancerous tissues as compared with adjacent normal mucosa. Subsequent western blotting confirmed that UHRF2 protein levels were significantly upregulated in cancerous tissues as compared with adjacent normal mucosa (Fig. 1C).

Association of UHRF2 TMA immunohistochemical staining with patient clinicopathological parameters. UHRF2 was observed mainly in the cytoplasm of colonic epithelial tumor cells, with nuclear staining only rarely observed by immunohistochemistry (Fig. 2). As shown in Table I, the distribution of UHRF2 expression was significantly different between normal and tumor tissues $(\mathrm{P}<0.001)$. Among the 203 normal mucosa specimens on the paired TMA, $132(65.0 \%)$ showed negative UHRF2 expression with weak staining in $38(18.7 \%)$ cases and strong staining in 33 (16.3\%) additional cases. However,
UHRF2 expression was obvious in the majority of colon tumor specimens, with weak staining in $57(28.1 \%)$ cases, strong staining in $75(36.9 \%)$ cases and negative staining in $71(35 \%)$ cases. This was also observed in patients with LNM or without LNM (Table I). The relationship between the expression of UHRF2 (immunohistochemical staining) and clinicopathological features is summarized in Table II. Expression (staining) of UHRF2 was highly correlated with the American Joint Committee on Cancer (AJCC) stage $(\mathrm{P}<0.001)$, T classification $(\mathrm{P}<0.001)$, nodal involvement $(\mathrm{P}<0.001)$, extent of tumor differentiation, recurrence and metastasis and the presence of distant metastasis $(\mathrm{P}<0.001)$. Factors not significantly associated with staining included age, gender, location of the tumor and vascular invasion.

Survival analysis and prognostic significance of UHRF2 expression. To assess the possible association between tumor UHRF2 expression and patient survival, Kaplan-Meier curves with a log-rank test for OS and DFS were undertaken (Fig. 3). 
Table II. Association between clinicopathological features and UHRF2 or Ki-67 protein expression.

\begin{tabular}{|c|c|c|c|c|c|}
\hline & & & RF2 expression & & \\
\hline & $\mathrm{n}$ & $\begin{array}{c}\text { Negative }(\mathrm{n}=71) \\
(\%)\end{array}$ & $\begin{array}{c}\text { Weak }(n=57) \\
(\%)\end{array}$ & $\begin{array}{c}\text { Strong }(\mathrm{n}=75) \\
(\%)\end{array}$ & P-value \\
\hline Age, years (n, \%) & & & & & 0.919 \\
\hline$<65$ & 81 & $29(40.8)$ & $23(40.4)$ & $29(38.7)$ & \\
\hline$\geq 65$ & 122 & $42(59.2)$ & $34(59.6)$ & $46(61.3)$ & \\
\hline Gender (n,\%) & & & & & 0.547 \\
\hline Male & 86 & $33(46.5)$ & $21(36.8)$ & $32(42.7)$ & \\
\hline Female & 117 & $38(53.5)$ & $36(63.2)$ & $43(57.3)$ & \\
\hline Location $(\mathrm{n}, \%)$ & & & & & 0.439 \\
\hline Right & 84 & $30(42.3)$ & $21(36.8)$ & $33(44.0)$ & \\
\hline Transverse & 19 & $9(12.7)$ & $4(7.0)$ & $6(8.0)$ & \\
\hline Left & 20 & $7(9.9)$ & $9(15.8)$ & $4(5.3)$ & \\
\hline Sigmoid colon & 80 & $25(35.2)$ & $23(40.4)$ & $32(42.7)$ & \\
\hline T stage $(\mathrm{n}, \%)^{\mathrm{b}}$ & & & & & $<0.001^{\mathrm{a}}$ \\
\hline $\mathrm{T} 1$ & 8 & $3(4.2)$ & $2(3.5)$ & $3(4.0)$ & \\
\hline $\mathrm{T} 2$ & 23 & $9(12.7)$ & $10(17.5)$ & $4(5.3)$ & \\
\hline $\mathrm{T} 3$ & 76 & $38(53.5)$ & $20(35.1)$ & $18(24.0)$ & \\
\hline $\mathrm{T} 4$ & 96 & $21(29.6)$ & $25(43.9)$ & $50(66.7)$ & \\
\hline $\mathrm{N}$ stage $(\mathrm{n}, \%)$ & & & & & $<0.001^{\mathrm{a}}$ \\
\hline NO & 108 & $53(76.4)$ & $32(56.1)$ & $23(30.7)$ & \\
\hline N1 & 61 & $15(21.1)$ & $14(24.6)$ & $32(42.7)$ & \\
\hline $\mathrm{N} 2$ & 34 & $3(4.2)$ & $11(19.3)$ & $20(26.7)$ & \\
\hline M stage $(\mathrm{n}, \%)^{\mathrm{b}}$ & & & & & $0.018^{\mathrm{a}}$ \\
\hline M0 & 185 & $69(97.2)$ & $53(93.0)$ & $63(84.0)$ & \\
\hline M1 & 18 & $2(2.8)$ & $4(7.0)$ & $12(16.0)$ & \\
\hline AJCC stage $(\mathrm{n}, \%)$ & & & & & $<0.001^{\mathrm{a}}$ \\
\hline I & 24 & $10(14.1)$ & $10(17.5)$ & $4(5.3)$ & \\
\hline II & 81 & $42(59.2)$ & $21(36.8)$ & $18(24.0)$ & \\
\hline III & 80 & $17(23.9)$ & $22(38.6)$ & $41(54.7)$ & \\
\hline IV & 18 & $2(2.8)$ & $4(7.0)$ & $12(16.0)$ & \\
\hline Differentiation $(\mathrm{n}, \%)$ & & & & & $<0.001^{\mathrm{a}}$ \\
\hline High & 99 & $46(64.8)$ & $29(50.9)$ & $24(32.0)$ & \\
\hline Moderate & 74 & $22(31.0)$ & $20(35.1)$ & $32(42.7)$ & \\
\hline Low & 30 & $3(4.2)$ & $8(14.0)$ & $19(25.3)$ & \\
\hline Vascular invasion $(\mathrm{n}, \%)^{\mathrm{b}}$ & & & & & 0.05 \\
\hline Yes & 189 & $71(98.6)$ & $55(96.5)$ & $63(85.1)$ & \\
\hline No & 14 & $1(1.4)$ & $2(3.5)$ & $11(14.9)$ & \\
\hline Ki-67 index $(\mathrm{n}, \%)$ & & & & & 0.165 \\
\hline Negative & 43 & $16(22.5)$ & $16(28.1)$ & $11(14.7)$ & \\
\hline Positive & 160 & $55(77.5)$ & $41(71.9)$ & $64(85.3)$ & \\
\hline
\end{tabular}

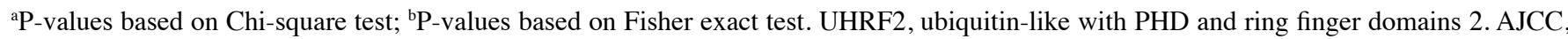
American Joint Committee on Cancer.

The 5-year OS rate of the 203 patients who underwent curative surgery with primary colon cancer was $68 \%$, with 65 deaths occurring during the follow-up. However, the 5-year DFS rate was $62 \%$, with 74 events occurring. Fifty-four patients (27\%) developed distant metastases and 20 patients (9\%) were diagnosed with local tumor recurrence. There was a considerable difference in the proportion of samples with metastasis or local recurrence from primary colon cancer between the UHRF2-positive and UHRF2-negative groups. More patients with UHRF2-positive tumors subsequently developed metastases or local recurrence than those with UHRF2-weak or UHRF2-negative tumors $(\mathrm{P}<0.001)$ [UHRF2-positive, 49 $(65.3 \%)$ of 70 patients; UHRF2-weak, 35 (29.9\%) of 53; UHRF2-negative, $8(10.7 \%)$ of 69 ]. Patients with negative 

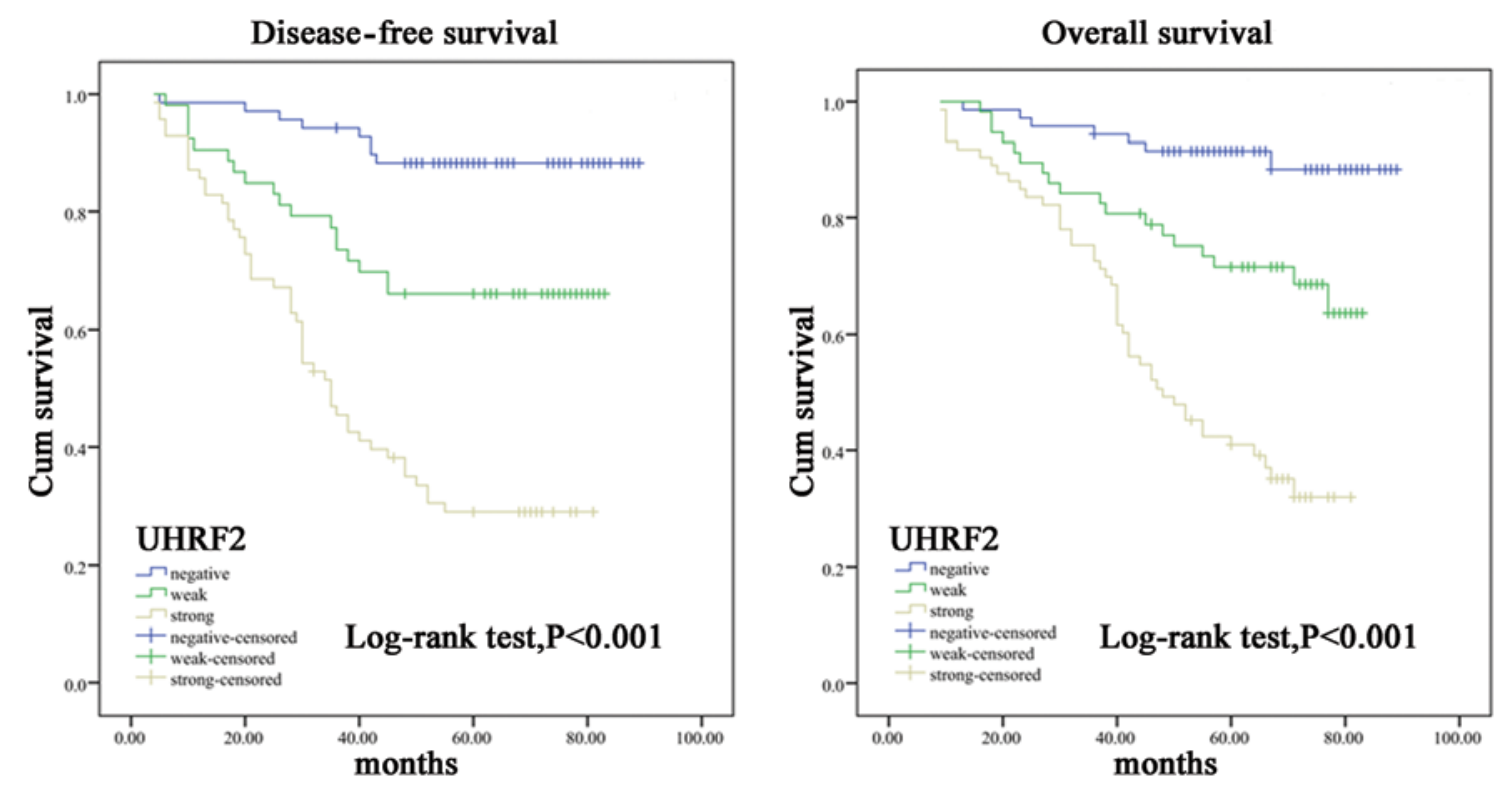

\begin{tabular}{|c|c|c|c|c|c|c|c|c|c|c|c|c|c|c|c|c|c|c|c|}
\hline & & \multicolumn{8}{|c|}{ Time (months) } & & & \multicolumn{8}{|c|}{ Time (months) } \\
\hline & & 0 & 12 & 24 & 36 & 48 & 60 & 72 & 84 & & & 0 & 12 & 24 & 36 & 48 & 60 & 72 & 84 \\
\hline \multirow[t]{2}{*}{ Negative } & A & 69 & 68 & 67 & 64 & 59 & 36 & 27 & 6 & Negative & A & 71 & 70 & 69 & 66 & 63 & 38 & 27 & 6 \\
\hline & B & 0 & 1 & 2 & 4 & 4 & 0 & 0 & 0 & & B & 0 & 1 & 1 & 2 & 2 & 0 & 1 & 0 \\
\hline \multirow[t]{2}{*}{ Weak } & A & 53 & 48 & 45 & 39 & 34 & 33 & 20 & 4 & Weak & A & 57 & 56 & 51 & 48 & 42 & 37 & 21 & 0 \\
\hline & B & 0 & 5 & 3 & 6 & 4 & 0 & 0 & 0 & & B & 0 & 1 & 5 & 3 & 4 & 3 & 4 & 0 \\
\hline \multirow[t]{2}{*}{ Strong } & A & 70 & 60 & 48 & 31 & 23 & 15 & 4 & 1 & Strong & A & 73 & 72 & 61 & 53 & 36 & 22 & 3 & 0 \\
\hline & B & 0 & 10 & 12 & 16 & 7 & 4 & 0 & 0 & & B & 0 & 1 & 11 & 8 & 17 & 6 & 4 & 0 \\
\hline
\end{tabular}

Figure 3. Kaplan-Meier analyses with a log-rank test of survival. Kaplan-Meier plots of disease-free survival (left) and overall survival (right) of patients with colon cancer who underwent curative resections on the basis of the immunohistochemical UHRF2 expression. UHRF2, ubiquitin-like with PHD and ring finger domains 2.

tumor UHRF2 expression had a better 5-year DFS and OS rate than did the group with positive-UHRF2 expression (DFS, $88.4 \%$ negative vs. $30 \%$ positive; OS, 91.4 vs. $29.5 \%$; $\mathrm{P}<0.001$, respectively). Kaplan-Meier curves showed that the rate of recurrence was significantly elevated with positive-UHRF2 expression (Fig. 3). The estimated mean OS was significantly different between patients with UHRF2-positive and UHRF2-negative tumors $(71.5 \pm 2.2$ and 58.6 \pm 5.0 months, respectively; $\mathrm{P}<0.001)$. The estimated mean DFS time was $66.2 \pm 2.4$ and $54.2 \pm 5.9$ months for subjects with UHRF2positive and UHRF2-negative tumors $(\mathrm{P}<0.001)$. The DFS and OS rates were significantly decreased with increasing UHRF2 expression (Fig. 3).

In univariate analysis, patients whose localized colon tumors were UHRF2-positive had a significantly lower 5-year DFS than those with UHRF2-negative tumors [HR 9.511 (95\% CI, 4.496-20.118)] (Fig. 3; Table III). The 5-year OS was also significantly lower in patients with UHRF2-positive tumors than in those with UHRF2-negative tumors [HR 9.820 (95\% CI, 4.405-21.891)] (Fig. 3; Table IV). In addition, $\mathrm{pT}$ stage $(\mathrm{P}<0.001), \mathrm{pN}$ stage $(\mathrm{P}<0.001)$, AJCC stage
$(\mathrm{P}<0.001)$, vascular invasion, Ki-67 expression and level of tumor differentiation $(\mathrm{P}<0.001)$ were associated with $\mathrm{OS}$ and DFS. To further define increased UHRF2 expression as an independent factor influencing tumor recurrence, multivariate analysis was performed using the Cox proportional hazards model for all of the significant variables in the univariate analysis (Tables III and IV); this demonstrated that positive tumor UHRF2 expression remained a significant independent prognostic factor for increased disease recurrence and decreased survival.

\section{Discussion}

The present study shows for the first time that overexpression of UHRF2 was significantly associated with cancer progression and metastasis independent of pathological Tumor-Node-Metastasis staging. The data support UHRF2 as a novel prognostic indicator of colon cancer outcomes; individuals with UHRF2-strong tumors have poorer OS and DFS as compared to those with UHRF2-negative tumors. Correlations of UHRF2 expression with advancing tumor 
Table III. Cox proportional hazards model univariate and multivariate analyses of individual parameters for correlations with disease-free survival (DFS).

\begin{tabular}{|c|c|c|c|c|c|c|}
\hline & \multicolumn{3}{|c|}{ Univariate analysis } & \multicolumn{3}{|c|}{ Multivariate analysis } \\
\hline & HR & CI & P-value & HR & CI & P-value \\
\hline $\begin{array}{l}\text { Age, years } \\
<65\end{array}$ & & & & & & \\
\hline$\geq 65$ & 1.063 & $0.647-1.749$ & 0.808 & & & \\
\hline $\begin{array}{l}\text { Gender } \\
\text { Male } \\
\text { Female }\end{array}$ & 1.221 & $0.745-2.002$ & 0.427 & & & \\
\hline $\begin{array}{l}\text { Tumor location } \\
\text { Right } \\
\text { Transverse } \\
\text { Left } \\
\text { Sigmoid colon }\end{array}$ & $\begin{array}{l}0.859 \\
1.135 \\
1.251\end{array}$ & $\begin{array}{l}0.328-2.252 \\
0.489-2.634 \\
0.731-2.140\end{array}$ & $\begin{array}{l}0.758 \\
0.768 \\
0.413\end{array}$ & & & \\
\hline $\begin{array}{l}\text { T stage } \\
\text { T1 } \\
\text { T2 } \\
\text { T3 } \\
\text { T4 }\end{array}$ & $\begin{array}{l}0.383 \\
0.125 \\
0.357\end{array}$ & $\begin{array}{l}0.093-1.580 \\
0.030-0.516 \\
0.204-0.625\end{array}$ & $\begin{array}{r}0.184 \\
0.004^{\mathrm{a}} \\
<0.001^{\mathrm{a}}\end{array}$ & $\begin{array}{l}0.418 \\
0.313 \\
0.439\end{array}$ & $\begin{array}{l}0.096-1.827 \\
0.072-1.372 \\
0.243-0.793\end{array}$ & $\begin{array}{l}0.247 \\
0.123 \\
0.006^{\mathrm{a}}\end{array}$ \\
\hline $\begin{array}{l}\text { N stage } \\
\text { N0 }\end{array}$ & & & & & & \\
\hline $\begin{array}{l}\mathrm{N} 1 \\
\mathrm{~N} 2\end{array}$ & $\begin{array}{r}3.433 \\
14.180\end{array}$ & $\begin{array}{l}1.809-6.515 \\
7.477-26.892\end{array}$ & $\begin{array}{l}<0.001^{\mathrm{a}} \\
<0.001^{\mathrm{a}}\end{array}$ & $\begin{array}{l}0.129 \\
0.246\end{array}$ & $\begin{array}{l}0.064-0.263 \\
0.133-0.453\end{array}$ & $\begin{array}{l}<0.001^{\mathrm{a}} \\
<0.001^{\mathrm{a}}\end{array}$ \\
\hline $\begin{array}{l}\text { M stage } \\
\text { M0 }\end{array}$ & & & & & & \\
\hline M1 & 9.028 & $4.322-18.855$ & $<0.001^{\mathrm{a}}$ & 0.295 & $0.135-0.649$ & $0.002^{\mathrm{a}}$ \\
\hline $\begin{array}{l}\text { AJCC stage } \\
\text { I+II } \\
\text { III+IV }\end{array}$ & 5.830 & $3.264-10.415$ & $<0.001^{\mathrm{a}}$ & & & \\
\hline $\begin{array}{l}\text { Differentiation } \\
\text { High } \\
\text { Moderate } \\
\text { Low }\end{array}$ & 2.340 & $1.306-4.193$ & $0.004^{\mathrm{a}}$ & & & \\
\hline $\begin{array}{l}\text { Vascular invasion } \\
\text { No } \\
\text { Yes }\end{array}$ & $\begin{array}{l}6.363 \\
5.162\end{array}$ & $\begin{array}{l}3.350-12.087 \\
2.735-9.742\end{array}$ & $\begin{array}{l}<0.001^{\mathrm{a}} \\
<0.001^{\mathrm{a}}\end{array}$ & & & \\
\hline $\begin{array}{l}\text { UHRF2 } \\
\text { Negative }\end{array}$ & & & & & & \\
\hline $\begin{array}{l}\text { Weak } \\
\text { Strong }\end{array}$ & $\begin{array}{r}4.352 \\
12.991\end{array}$ & $\begin{array}{l}1.660-12.7366 \\
5.144-32.813\end{array}$ & $\begin{array}{r}0.003^{\mathrm{a}} \\
<0.001^{\mathrm{a}}\end{array}$ & $\begin{array}{l}0.145 \\
0.483\end{array}$ & $\begin{array}{l}0.056-0.378 \\
0.268-0.872\end{array}$ & $\begin{array}{r}<0.001^{\mathrm{a}} \\
0.016^{\mathrm{a}}\end{array}$ \\
\hline $\begin{array}{l}\text { Ki-67 } \\
\text { Negative }\end{array}$ & & & & & & \\
\hline $\begin{array}{l}\text { Weak } \\
\text { Positive }\end{array}$ & $\begin{array}{l}2.090 \\
2.102\end{array}$ & $\begin{array}{l}0.914-4.778 \\
1.023-4.321\end{array}$ & $\begin{array}{l}0.081 \\
0.043^{\mathrm{a}}\end{array}$ & & & \\
\hline
\end{tabular}

AJCC, American Joint Committee on Cancer; CI, confidence interval; HR, hazard ratio; UHRF2, ubiquitin-like with PHD and ring finger domains 2. ${ }^{a}<0.05$ indicated that the $95 \% \mathrm{CI}$ of $\mathrm{HR}$ was not including I.

stages suggest that UHRF2 may contribute to the progression of colon carcinogenesis.

In the fresh colon tissues examined in the present study, real-time PCR, immunostaining and western blotting showed that the elevated expression of UHRF2 occurred both at the transcriptional and post-transcriptional levels. In addition, we found that elevated expression of UHRF2 correlated with several clinicopathological factors including AJCC stage 
Table IV. Cox proportional hazards model univariate and multivariate analyses of individual parameters for correlations with overall survival (OS).

\begin{tabular}{|c|c|c|c|c|c|c|}
\hline & \multicolumn{3}{|c|}{ Univariate analysis } & \multicolumn{3}{|c|}{ Multivariate analysis } \\
\hline & HR & CI & P-value & HR & CI & P-value \\
\hline $\begin{array}{l}\text { Age } \\
<65\end{array}$ & & & & & & \\
\hline$\geq 65$ & 1.038 & $0.653-1.651$ & 0.875 & & & \\
\hline $\begin{array}{l}\text { Gender } \\
\text { Male } \\
\text { Female }\end{array}$ & 0.747 & $0.463-1.197$ & 0.223 & & & \\
\hline $\begin{array}{l}\text { Tumor location } \\
\text { Right } \\
\text { Transverse } \\
\text { Left } \\
\text { Sigmoid colon }\end{array}$ & $\begin{array}{l}0.940 \\
0.751 \\
0.901\end{array}$ & $\begin{array}{l}0.568-1.554 \\
0.314-1.797 \\
0.397-2.401\end{array}$ & $\begin{array}{l}0.808 \\
0.520 \\
0.802\end{array}$ & & & \\
\hline $\begin{array}{l}\text { T stage } \\
\text { T1 } \\
\text { T2 } \\
\text { T3 } \\
\text { T4 }\end{array}$ & $\begin{array}{l}0.356 \\
0.108 \\
0.337\end{array}$ & $\begin{array}{l}0.087-1.461 \\
0.026-0.443 \\
0.197-0.578\end{array}$ & $\begin{array}{c}0.152 \\
0.002^{\mathrm{a}} \\
<0.001^{\mathrm{a}}\end{array}$ & $\begin{array}{l}0.211 \\
0.291 \\
0.410\end{array}$ & $\begin{array}{l}0.047-0.950 \\
0.067-1.266 \\
0.230-0.732\end{array}$ & $\begin{array}{l}0.043^{\mathrm{a}} \\
0.100 \\
0.003^{\mathrm{a}}\end{array}$ \\
\hline $\begin{array}{l}\text { N stage } \\
\text { N0 }\end{array}$ & & & & & & \\
\hline $\begin{array}{l}\mathrm{N} 1 \\
\mathrm{~N} 2\end{array}$ & $\begin{array}{l}0.071 \\
0286\end{array}$ & $\begin{array}{l}0.038-0.133 \\
0.167-0.488\end{array}$ & $\begin{array}{l}<0.001^{\mathrm{a}} \\
<0.001^{\mathrm{a}}\end{array}$ & $\begin{array}{l}2.351 \\
7.142\end{array}$ & $\begin{array}{l}1.211-4.562 \\
3.640-14.743\end{array}$ & $\begin{array}{r}0.012^{\mathrm{a}} \\
<0.001^{\mathrm{a}}\end{array}$ \\
\hline $\begin{array}{l}\text { M stage } \\
\text { M0 }\end{array}$ & & & & & & \\
\hline M1 & 0.068 & $0.037-0.123$ & $<0.001^{\mathrm{a}}$ & 7.528 & $3.823-14.820$ & $<0.001^{\mathrm{a}}$ \\
\hline $\begin{array}{l}\text { AJCC stage } \\
\text { I+II } \\
\text { III+IV }\end{array}$ & 6.663 & $3.755-11.821$ & $0.000^{\mathrm{a}}$ & & & \\
\hline $\begin{array}{l}\text { Differentiation } \\
\text { High }\end{array}$ & & & & & & \\
\hline $\begin{array}{l}\text { Moderate } \\
\text { Low }\end{array}$ & $\begin{array}{l}2.368 \\
7.499\end{array}$ & $\begin{array}{l}1.342-4.178 \\
4.112-13.678\end{array}$ & $\begin{array}{r}0.003^{\mathrm{a}} \\
<0.001^{\mathrm{a}}\end{array}$ & & & \\
\hline $\begin{array}{l}\text { No } \\
\text { Yes }\end{array}$ & 4.677 & $2.545-8.595$ & $<0.001^{\mathrm{a}}$ & & & \\
\hline $\begin{array}{l}\text { UHRF2 } \\
\text { Negative }\end{array}$ & & & & & & \\
\hline $\begin{array}{l}\text { Weak } \\
\text { Strong }\end{array}$ & $\begin{array}{l}3.651 \\
9.820\end{array}$ & $\begin{array}{l}1.518-8.783 \\
4.405-21.891\end{array}$ & $\begin{array}{r}0.004^{\mathrm{a}} \\
<0.001^{\mathrm{a}}\end{array}$ & $\begin{array}{l}2.361 \\
4.205\end{array}$ & $\begin{array}{l}0.965-5.778 \\
1.805-9.793\end{array}$ & $\begin{array}{l}0.060 \\
<0.001^{\mathrm{a}}\end{array}$ \\
\hline $\begin{array}{l}\text { Ki-67 } \\
\text { Negative }\end{array}$ & & & & & & \\
\hline $\begin{array}{l}\text { Weak } \\
\text { Positive }\end{array}$ & $\begin{array}{l}2.302 \\
3.096\end{array}$ & $\begin{array}{l}0.917-5.775 \\
1.406-6.817\end{array}$ & $\begin{array}{r}0.076^{\mathrm{a}} \\
<0.005^{\mathrm{a}}\end{array}$ & & & \\
\hline
\end{tabular}

AJCC, American Joint Committee on Cancer; CI, confidence interval; HR, hazard ratio; UHRF2, ubiquitin-like with PHD and ring finger domains 2. ${ }^{\mathrm{a}} \mathrm{P}<0.05$ indicated that the $95 \% \mathrm{CI}$ of HR was not including I.

$(\mathrm{P}<0.001), \mathrm{T}$ classification $(\mathrm{P}<0.001)$, nodal involvement $(\mathrm{P}<0.001)$, extent of differentiation $(\mathrm{P}<0.001)$ and the presence of distant metastasis $(\mathrm{P}=0.018)$.

The UHRF family, including UHRF2 and UHRF1, is considered to be involved in carcinogenesis (11). UHRF2 is a multidomain protein with 802 amino acid residues that shows high structural similarity to its close homolog UHRF1, a putative oncogenic factor, suggested to be an important biomarker to discriminant several types of cancer (21-23). However, in sharp contrast to UHRF1, the UHRF2 gene is frequently 
discrepant in tumorigenesis. In the present study, UHRF2 acted as an oncogene in the development and progression of colon cancer, which is in accordance with the role UHRF2 plays in breast cancer. However, other reports have elucidated its role of tumor suppression in malignant glioma (24). This apparent contradiction arises since UHRF2 is a multiple functional protein that is involved in the coordination of three different network modules as previously demonstrated. It is common knowledge that cancer results from an accumulation of genetic and epigenetic aberrations (1). Thus, we speculate that UHRF2 may have an oncogenic role in colon cancer by mediating tumor suppressor gene inactivation via both DNA methylation and histone modification pathway development and may promote tumor progression through ubiquitin-mediated degradation of the suppressor such as P53 in colon cancer. It is known that inhibiting the proteasome pathways is a notable strategy for anticancer drug development (25) and UHRF2 is a ubiquitin E3 ligase. Targeting UHRF2 would selectively stabilize a specific cellular protein regulated by it, thus avoiding unwanted effects on other cellular proteins. In brief, UHRF2 is a potential novel therapeutic target in colon cancer.

In recent years, our understanding of the metastatic process has significantly evolved. However, the mechanisms involved in colon cancer metastasis are not fully understood as metastasis is a multistep process and requires altered expression of a spectrum of genes (26). In the present study, we examined the expression of UHRF2 in 95 samples of primary colon cancer with metastasis and 108 samples of primary colon cancer without metastasis. There is a significant difference between them $(\mathrm{P}<0.001)$. The expression of UHRF2 was upregulated in the specimens with metastasis compared with those without metastasis (54.7 vs. $21.3 \%$ ). Finally, our results provide the first evidence that the expression of UHRF2 may be a potential molecular marker. UHRF2 expression was associated with an increased risk of metastasis/local recurrence and was strongly linked to poor survival outcomes, with hazard ratios of 9.511 for DFS and 9.820 for OS in the univariate analysis. In multivariate analysis, UHRF2 expression appeared to be an independent prognostic factor for OS and DFS in colon cancer.

The present study found that increased UHRF2 expression was observed in colon cancer tissue and was associated with multiple clinicopathological factors as well as patient OS and DFS. Further studies are necessary to evaluate the mechanism by which UHRF2 is upregulated in colon cancer, the role of UHRF2 in colon cancer progression as well as its value in the prognosis of this disease.

\section{Acknowledgements}

This study was supported by the Key Basic Research Project of the Science and Technology Commission of Shanghai (11JC1410200), the National Natural Science Foundation of China (81072008, 81172328), the Medical Guidance Project of Shanghai Science and Technology Commission (114119a4600, 124119a1700).

\section{References}

1. Vogelstein B and Kinzler KW: Cancer genes and the pathways they control. Nat Med 10: 789-799, 2004.
2. Siegel R, Naishadham D and Jemal A: Cancer statistics, 2012. CA Cancer J Clin 62: 10-29, 2012.

3. Jemal A, Siegel R, Ward E, Hao Y, Xu J and Thun MJ: Cancer statistics, 2009. CA Cancer J Clin 59: 225-249, 2009.

4. Zhang S, Cui Y, Weng Z, Gong X, Chen M and Zhong B: Changes on the disease pattern of primary colorectal cancers in Southern China: a retrospective study of 20 years. Int J Colorectal Dis 24: 943-949, 2009.

5. Petrova TV, Nykänen A, Norrmén C, et al: Transcription factor PROX 1 induces colon cancer progression by promoting the transition from benign to highly dysplastic phenotype. Cancer Cell 13: 407-419, 2008.

6. Sansom OJ, Meniel VS, Muncan V, et al: Myc deletion rescues Apc deficiency in the small intestine. Nature 446: 676-679, 2007.

7. Micel LN, Tentler JJ, Smith PG and Eckhardt GS: Role of ubiquitin ligases and the proteasome in oncogenesis: novel targets for anticancer therapies. J Clin Oncol 31: 1231-1238, 2013.

8. Bedford L, Lowe J, Dick LR, Mayer RJ and Brownell JE: Ubiquitin-like protein conjugation and the ubiquitin-proteasome system as drug targets. Nat Rev Drug Discov 10: 29-46, 2011.

9. Reinstein $E$ and Ciechanover A: Narrative review: protein degradation and human diseases: the ubiquitin connection. Ann Intern Med 145: 676-684, 2006.

10. Naujokat $\mathrm{C}$ and Sarić T: Concise review: role and function of the ubiquitin-proteasome system in mammalian stem and progenitor cells. Stem Cells 25: 2408-2418, 2007.

11. Bronner C, Achour M, Arima Y, Chataigneau T, Saya H and Schini-Kerth VB: The UHRF family: oncogenes that are drugable targets for cancer therapy in the near future? Pharmacol Ther 115: 419-434, 2007.

12. Hopfner R, Mousli M, Jeltsch JM, et al: ICBP90, a novel human CCAAT binding protein, involved in the regulation of topoisomerase II $\alpha$ expression. Cancer Res 60: 121-128, 2000.

13. Mori T, Li Y, Hata H, Ono K and Kochi H: NIRF, a novel RING finger protein, is involved in cell-cycle regulation. Biochem Biophys Res Commun 296: 530-536, 2002.

14. Kotliarov Y, Steed ME, Christopher N, et al: High-resolution global genomic survey of 178 gliomas reveals novel regions of copy number alteration and allelic imbalances. Cancer Res 66: 9428-9436, 2006.

15. Wu J, Liu S, Liu G, et al: Identification and functional analysis of 9p24 amplified genes in human breast cancer. Oncogene 31: 333-341, 2012.

16. Li DW, Tang HM, Fan JW, et al: Expression level of Bmi-1 oncoprotein is associated with progression and prognosis in colon cancer. J Cancer Res Clin Oncol 136: 997-1006, 2010.

17. Yan DW, Fan JW, Yu ZH, et al: Downregulation of metallothionein $1 \mathrm{~F}$, a putative oncosuppressor, by loss of heterozygosity in colon cancer tissue. Biochim Biophys Acta 1822: 918-926, 2012.

18. Troup S, Njue C, Kliewer EV, et al: Reduced expression of the small leucine-rich proteoglycans, lumican, and decorin is associated with poor outcome in node-negative invasive breast cancer. Clin Cancer Res 9: 207-214, 2003.

19. Bachmann IM, Puntervoll HE, Otte AP and Akslen LA: Loss of BMI-1 expression is associated with clinical progress of malignant melanoma. Mod Pathol 21: 583-590, 2008.

20. Hashimoto Y, Skacel M, Lavery IC, Mukherjee AL, Casey G and Adams JC: Prognostic significance of fascin expression in advanced colorectal cancer: an immunohistochemical study of colorectal adenomas and adenocarcinomas. BMC Cancer 6: 241, 2006.

21. Lorenzato M, Caudroy S, Bronner C, et al: Cell cycle and/or proliferation markers: what is the best method to discriminate cervical high-grade lesions? Hum Patho 36: 1101-1107, 2005.

22. Crnogorac-Jurcevic T, Gangeswaran R, Bhakta V, et al: Proteomic analysis of chronic pancreatitis and pancreatic adenocarcinoma. Gastroenterology 129: 1454-1463, 2005.

23. Unoki M, Kelly JD, Neal DE, Ponder BA, Nakamura Y and Hamamoto R: UHRF1 is a novel molecular marker for diagnosis and the prognosis of bladder cancer. Br J Cancer 101: 98-105, 2009.

24. Wu TF, Zhang W, Su ZP, et al: UHRF2 mRNA expression is low in malignant glioma but silencing inhibits the growth of U251 glioma cells in vitro. Asian Pac J Cancer Prev 13: 5137-5142, 2012.

25. Sun Y: E3 ubiquitin ligases as cancer targets and biomarkers. Neoplasia 8: 645-654, 2006.

26. Ma C, Rong Y, Radiloff DR, et al: Extracellular matrix protein ßig-h3/TGFBI promotes metastasis of colon cancer by enhancing cell extravasation. Genes Dev 22: 308-321, 2008 